\title{
LUMBO-SACRAL SUBLUXATION
}

\author{
(Group 1 Spondylolisthesis)
}

\author{
D. J. Dandy and M. J. Shannon, London, England \\ Dawn Trust Unit for Spinal Research, the Institute of Orthopaedics, \\ Royal National Orthopaedic Hospital, London and Stanmore
}

In 1854 Kilian first described as spondylolisthesis the condition then known as luxation of the lumbo-sacral joint. The terms prespondylolisthesis, pseudospondylolisthesis, retrolisthesis, retrospondylolisthesis, spondyloptosis and spondylolysis have since been introduced and much of the argument surrounding the subject has been semantic. Confusion has also arisen from the belief that spondylolisthesis must have a single cause.

Early writers found a defect in the pars interarticularis of affected vertebrae, whereas Neugebauer (1888) found the arch intact but elongated. The existence of a defect in the pars interarticularis slowly came to be accepted, and disagreement shifted to its cause, some authors believing it a congenital error of development while others held it to be a fracture. Meyerding (1931, 1938) found evidence of defects of the pars interarticularis in many patients with low back pain and stated that spondylolisthesis was far commoner than had been thought, many cases passing without diagnosis. He also suggested that men were affected more often than women, the reverse of previous reports.

These differences were partly reconciled by Capener in 1932 when he pointed out the existence of two distinct types of spondylolisthesis, one with a defect in the pars interarticularis and a less common variety with an intact but narrowed pars interarticularis of the fifth lumbar vertebra and a defect in the roof of the sacrum; he observed that the second type often showed severe displacement. Spondylolisthesis was again subdivided by Newman, who in 1963 separated 319 cases into five groups. The different causes of spondylolisthesis then included a congenital anomaly of the lumbo-sacral junction, a stress fracture, an acute fracture, degenerative joint disease and generalised bone disease. The word "spondylolisthesis" means only a slipping vertebra, and its use as a diagnosis without qualification is not acceptable.

The patients included in this study had the condition previously referred to as severe lumbo-sacral subluxation (Newman 1965), Group 1 spondylolisthesis (Newman 1963), spondyloptosis (Neugebauer 1888), the smaller and rarer group of Capener (1932) and spondylolisthesis with tight hamstrings (Phalen and Dickson 1961; Barash, Galante, Lambert and Ray 1970). In Newman's (1963) series 20.7 per cent of his 319 cases were of this type and showed a ratio of $2 \cdot 3$ females to 1 male. The diagnosis is suggested clinically by an obvious deformity (Newman 1965) (Fig. 1). It seems probable that the clinical condition first described as spondylolisthesis over a century ago, before the advent of radiography, was the same condition as that studied in this report. This hypothesis would explain Meyerding's comment that early studies showed a higher incidence in women.

Although marked displacement is more accurately described as luxation than subluxation, it is suggested that if the term "lumbo-sacral subluxation" were used to identify the type of spondylolisthesis here described there would be less confusion with other varieties of the condition.

\section{AIMS AND METHOD OF STUDY}

This study was designed to review the clinical and radiological features and progress of patients having Group 1 (congenital) spondylolisthesis (lumbo-sacral subluxation) who came 


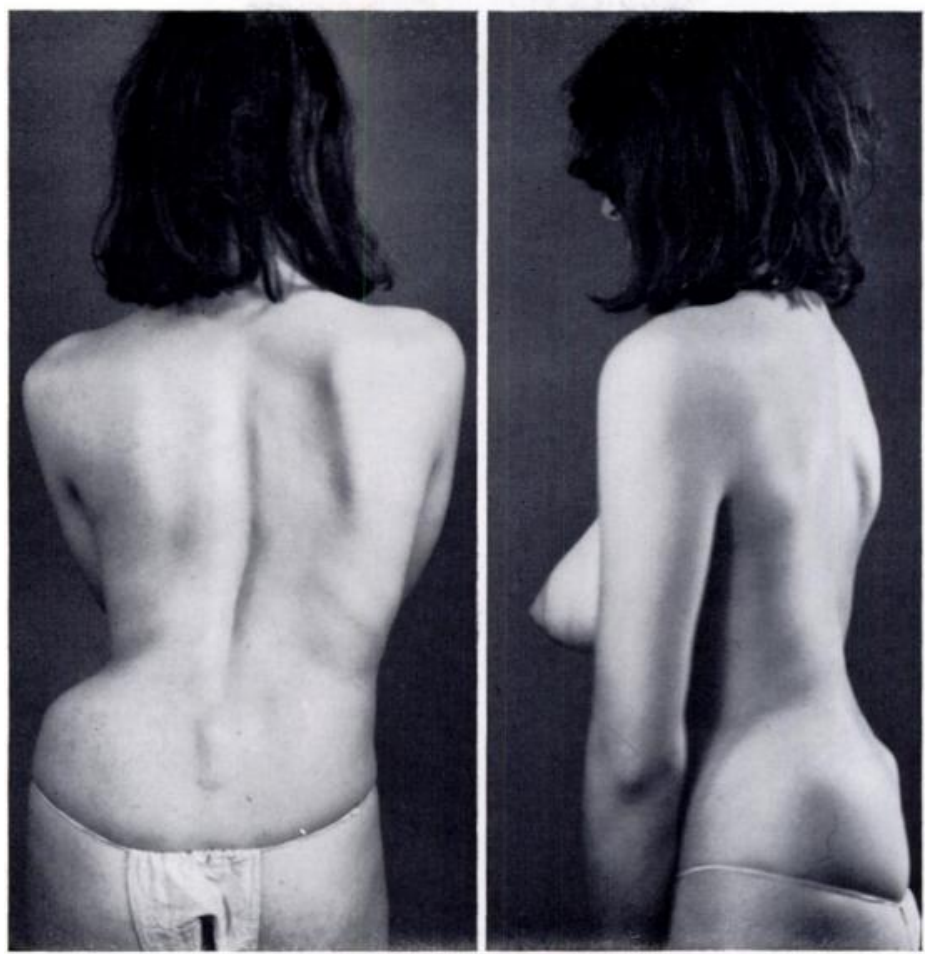

FiG. 1

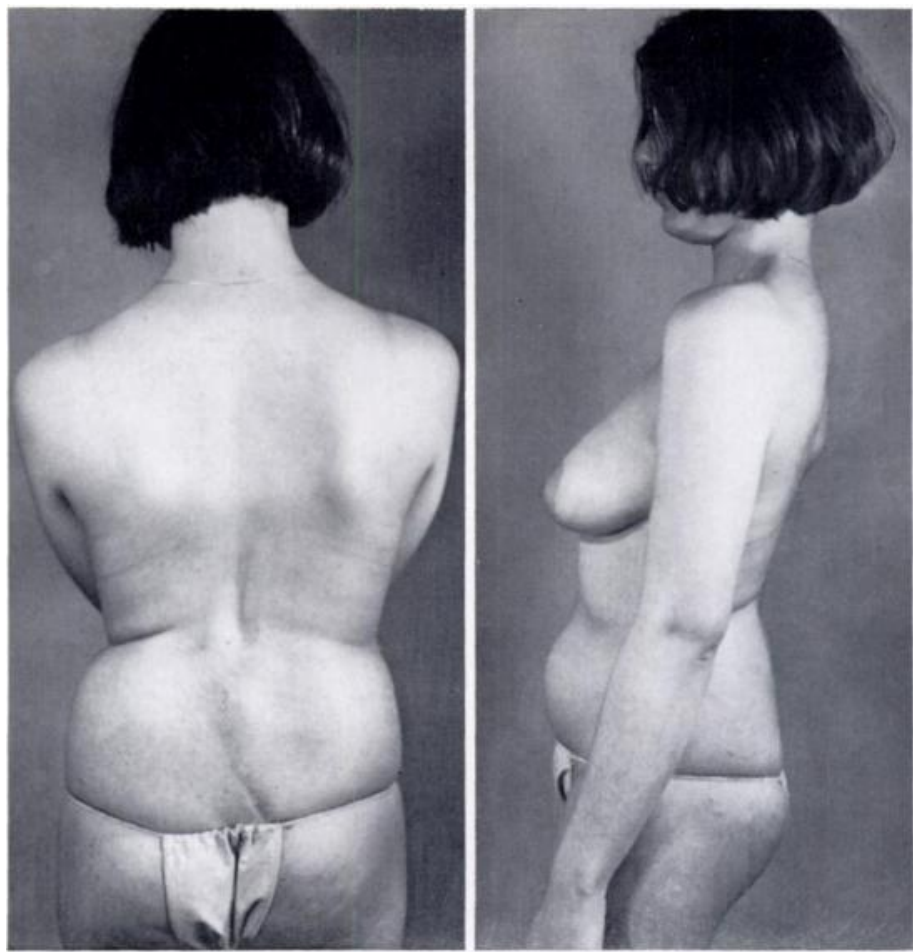

FIG. 2

The typical deformity of lumbo-sacral subluxation. Figure 1-Before operation. Figure 2-The same patient six months after lumbo-sacral fusion.

VOL. 53 B, NO. 4, NOVEMBFR 1971 
under the care of Mr P. H. Newman at the Royal National Orthopaedic Hospital during a period of twenty-three years. The criteria for inclusion in this group were those used by Newman (1963): 1) lumbo-sacral subluxation, usually of marked degree (Fig. 3); 2) deficient development of the sacral neural arches (Figs. 4 to 6); 3) deficient development of the superior sacral articular facets, which are unable to resist the forces imposed upon them by the lumbar

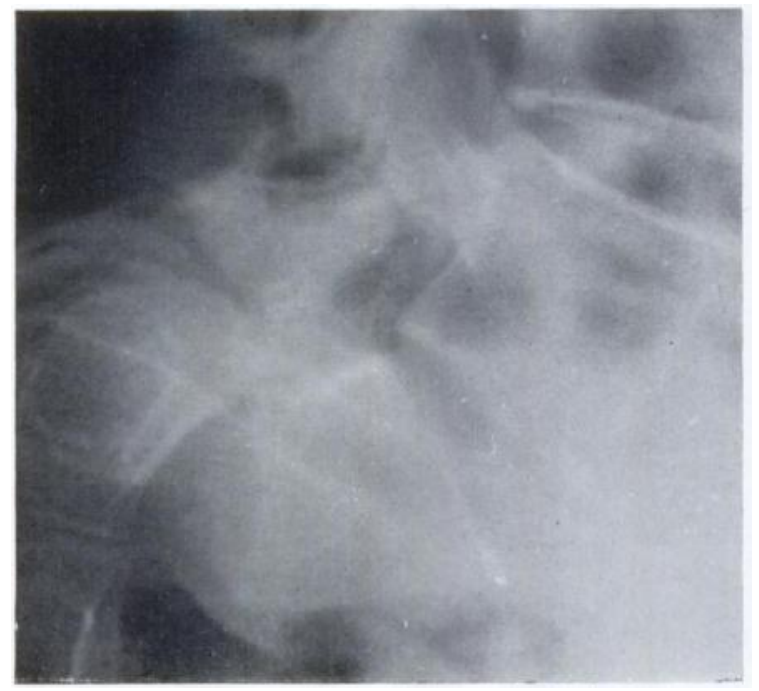

FIG. 3

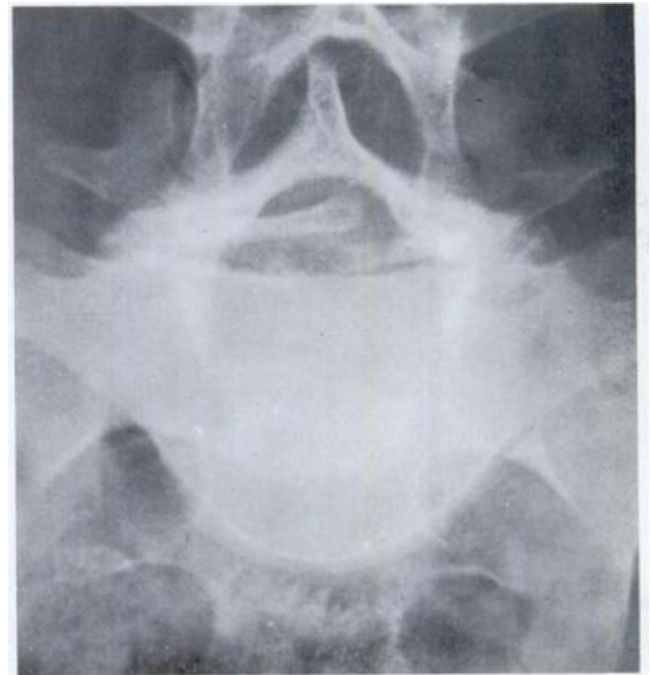

Fig. 4

Figure 3 Severe lumbo-sacral subluxation. Figure 4-An antero-posterior radiograph showing absence of the sacral roof and an incomplete neural arch of the fifth lumbar vertebra.

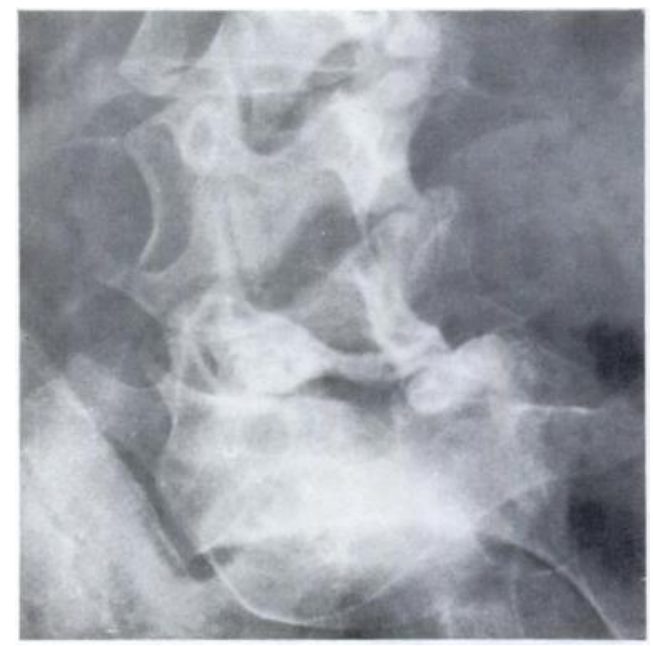

FIG. 5

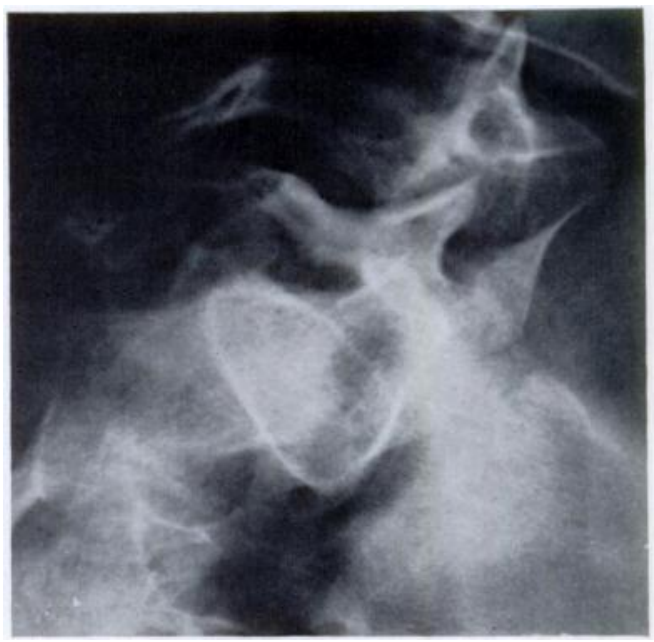

Fig. 6

Figure 5-An oblique radiograph showing deficient sacral articular facets and absence of the sacral roof. Figure 6-An oblique radiograph showing the attenuated but intact pars interarticularis of the fifth lumbar vertebra.

thrust (Fig. 5): and 4) attenuation and elongation of the pars interarticularis, with or without a defect in continuity (Figs. 6 and 7).

The study was conducted and is presented in three parts: 1) examination of clinical notes to record the clinical features, treatment and progress of patients; 2) examination of serial radiographs with particular reference to the radiological criteria for diagnosis, the rate of 
displacement and the effect of treatment upon this; and 3) clinical review of the effects of treatment in patients who attended a clinic arranged specially for this purpose.

Patients were included in this study only if there were adequate clinical details of their

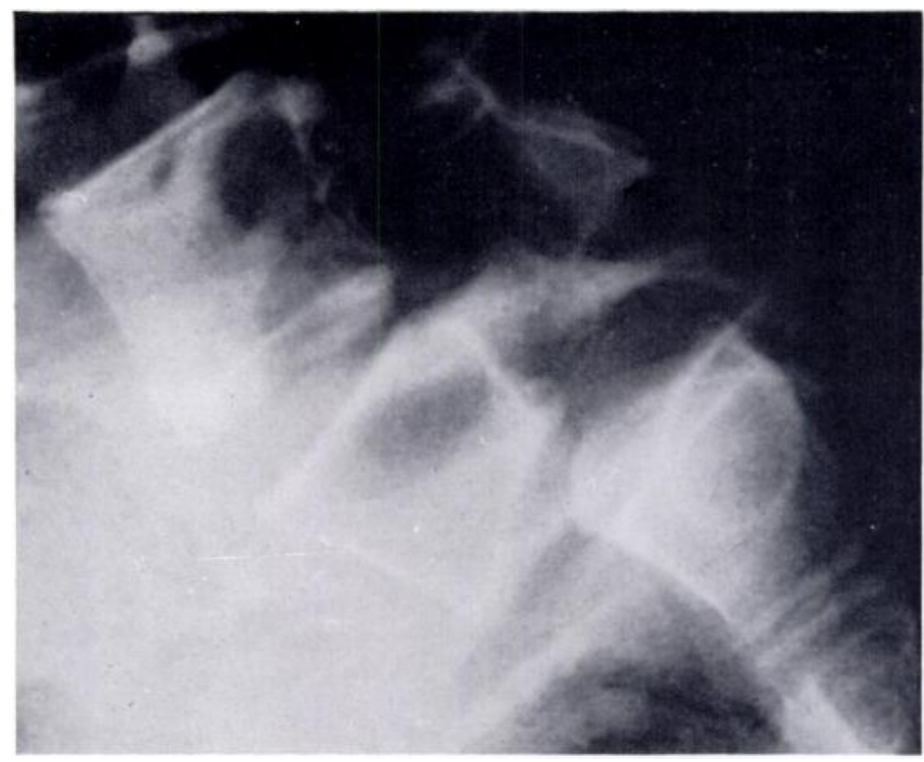

FIG. 7

A lateral radiograph showing an attenuated but intact pars interarticularis of the fifth lumbar vertebra.

condition before and after operation and adequate serial radiographs; they were excluded from the study if they had undergone operation within two years of review.

Forty-six patients remained available for study, of whom forty-two had undergone spinal fusion. We were able to trace and examine twenty-seven patients.

\section{EXAMINATION OF CLINICAL NOTES}

Sex incidence-Of the forty-six patients thirty-one were female and fifteen male. Age incidence-Newman (1963) pointed out that patients with lumbo-sacral subluxation develop symptoms either during the adolescent growth spurt or in the third or fourth decades of life.

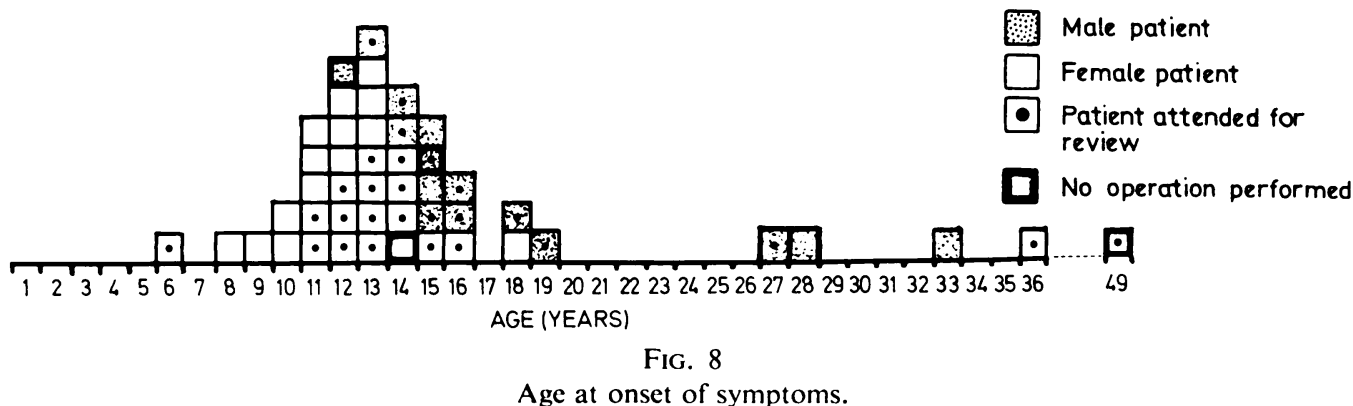

In the present series the average age of patients at onset of symptoms was 15.7 years (Fig. 8). Forty-one patients noticed symptoms before the age of twenty. In these the average age of onset was 15.5 years in males and 11.9 years in females. More than half the females 
had symptoms within a year of the menarche. Only one patient developed symptoms before the age of eight years and she began menstruating at nine years.

History of injury-Sixteen patients gave a definite history of injury to the back which they related to the onset of symptoms.

Symptoms and signs-The initial symptoms in the forty-six patients are shown in Table I.

Pain-When first seen at the Royal National Orthopaedic Hospital all forty-six patients were complaining of pain. Thirty-six had back pain and forty had pain in one or more other

TABLE I

INITIAL SYMPTOMS

\begin{tabular}{|l|c|}
\hline \multicolumn{1}{|c|}{ Symptom } & Number \\
\hline Pain . & 42 \\
Stiffness & 12 \\
Deformity $\cdot$ & 11 \\
Paraesthesia $\cdot$ & 17 \\
Weakness & 1 \\
\hline
\end{tabular}

TABLE II

The Features of the Pain in Forty-six Patients

\begin{tabular}{|c|c|c|c|c|}
\hline & & $\begin{array}{l}\text { Number of } \\
\text { patients }\end{array}$ & & $\begin{array}{c}\text { Number of } \\
\text { patients }\end{array}$ \\
\hline \multirow[t]{5}{*}{ Site } & Back. & 36 & Factors aggravating pain & \\
\hline & Buttock & 17 & Standing . & 27 \\
\hline & Thigh & 28 & Sitting . & 17 \\
\hline & Leg . & 19 & Bending or lifting & 20 \\
\hline & Foot. & 5 & Coughing or sneezing & 15 \\
\hline \multirow[t]{2}{*}{ Onset } & Gradual . & 31 & Movement & 14 \\
\hline & Sudden & 15 & Factors relieving pain & \\
\hline \multirow[t]{2}{*}{ Nature } & Dull. & 41 & Lying down . & 25 \\
\hline & Sharp & 5 & Change of position & 11 \\
\hline \multirow[t]{3}{*}{ Severity } & Mild. & 8 & & \\
\hline & Moderate & 28 & & \\
\hline & Severe & 10 & & \\
\hline \multirow[t]{2}{*}{ Constancy } & Intermittent & 21 & & \\
\hline & Constant & 25 & & \\
\hline
\end{tabular}

sites, most commonly the buttock (seventeen), the back of the thigh (twenty-eight) or the leg (nineteen). Thirty-one stated that the pain was of gradual onset and fifteen that it occurred suddenly, usually after an injury. Forty-one patients described the pain as predominantly a dull ache and five described a sharp lancinating pain radiating to the foot. Ten patients described the pain as extremely severe, twenty-eight as moderately severe and eight as mild. 
Twenty-five patients said the pain was continuous. These features are summarised in Table II which also lists the most common factors aggravating and relieving pain.

Stiffiness-Twenty-two patients complained of stiffness, which was a significant problem in fourteen.

Neurological symptoms - Twenty-one patients complained of paraesthesiae; three patients also complained of weakness and two of incontinence. In approximately half these twenty-one patients the symptoms were important.

Deformity-All patients showed the typical clinical deformity of severe spondylolisthesis, which includes lumbar lordosis and loss of pelvic tilt, a palpable step at the lumbo-sacral junction and foreshortening of the trunk shown by skin creases in the loin and proximity of the costal margin to the iliac crest (Fig. 1). Twenty-six patients also had scoliosis of varying amount.

Movement-Forward flexion was restricted in most patients - only eight patients could touch their toes and eighteen could not reach below their knees. In thirty patients straight leg raising was less than 80 degrees on one or both sides, the average being 55 degrees. When the limit of straight leg raising was reached the buttock would lift off the couch with no pain or discomfort.

Neurological signs-Objective neurological signs were present in eighteen patients, of whom fifteen had abnormal reflexes (commonly loss of an ankle jerk), six had altered sensibility and four had motor weakness.

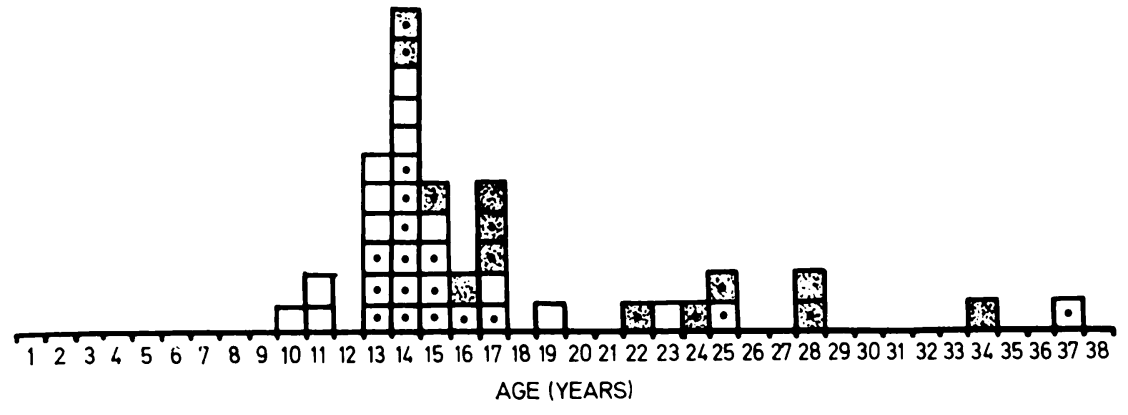

FIG. 9

Age at operation.

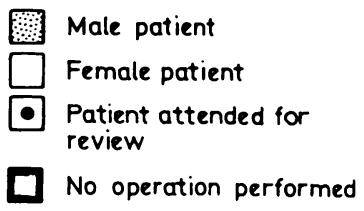

KEY TO FIGURES $9-10$

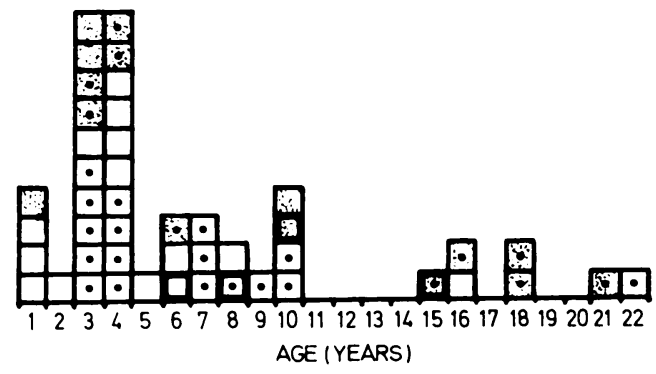

FIG. 10

The intervals between spinal fusion (or the date of presentation if no operation was performed) and the most recent examination.

Conservative treatment-Thirty patients had a significant period of conservative treatment. Several methods of treatment were used including bed rest, traction, corset, plaster jacket and physiotherapy. Four patients had lasting improvement of their symptoms and were not subjected to operation. Three of these were among the patients whose symptoms began in adult life. Eight of the thirty patients had temporary relief of symptoms, thirteen had no 
relief and five were made worse. These five included two patients early in the series in whom reduction of the displacement was attempted by pelvic suspension; both developed neurological abnormalities and incontinence of urine. One patient made a complete recovery but the other remained incontinent of urine and has residual weakness of the lower limbs. Pelvic suspension has been abandoned as a method of treatment.

Operative treatment-Forty-two patients were subjected to lumbo-sacral fusion (Fig. 9). In the earlier cases posterior fusion was performed, but in recent years intertransverse fusion was used. Only two patients had anterior spinal fusion.

A graft of autogenous bone was obtained from the posterior part of the ilium in almost all cases and no internal fixation was used. In seven cases the neural canal was decompressed, usually for a significant neurological defect, and in each case it was found that the adjoining borders of the fourth and fifth laminae were indenting the spinal theca. Immobilisation after operation was provided by a plaster bed for two or three months followed by a corset or a plaster jacket for a similar period. Patients then began a course of gentle mobilising exercises. The average time of return to work or school after operation was four months.

Progress-The clinical notes record that a year after operation thirty-six patients were completely relieved of pain and six partly relieved. More than half could touch their toes and all could reach below the middle of the tibiae. Straight leg raising was at least 80 degrees in all except three patients. The deformity was often less obvious after operation (Fig. 2) than before.

Complications-There were no serious complications except those produced by pelvic suspension already mentioned. Two scars were painful, two wounds were slow to heal and one wound became infected. Two patients developed urinary infection. Five patients developed neurological changes after operation; two of these had transient isolated muscle weakness and three had localised sensory changes which improved but did not recover completely. No thrombo-embolic complications or respiratory problems were recorded.

\section{RADIOLOGICAL STUDY}

The radiological study was conducted in two parts: the examination of radiographs for the presence or absence of certain features, and the measurement of the rate of displacement of one vertebra upon the other, with special note of the effect upon this of the operation.

\section{SPECIFIC RADIOLOGICAL FEATURES}

The four radiological signs needed for inclusion in this study were present in all patients. These were: 1) lumbo-sacral subluxation (Fig. 3); 2) deficient development of the sacral neural arches (Figs. 4 to 6);3) deficient development of the superior sacral articular facets, which are unable to resist the forces imposed upon them by the lumbar thrust (Fig. 5); and 4) attenuation and elongation of the pars interarticularis of the fifth lumbar vertebra (Figs. 6 and 7).

The following radiographic features were also sought.

Defect in continuity in the pars interarticularis of the fifth lumbar vertebra-It is often difficult to be certain of the presence of a defect in the narrowed pars interarticularis. The findings at operation were often more help than examination of the radiograph. Of the forty-six patients, thirty-two had a defect on one or both sides, visible in radiographs (Fig. 3).

Defect in the spine of the fifth lumbar vertebra-Twenty patients of forty-six had a deficient spinous process of the fifth lumbar vertebra; in contrast, Brailsford (1929) found the incidence of this abnormality in a series of 3,000 unselected radiographs to be 6 per cent. One patient had also deficient spinous processes on the eleventh and twelfth thoracic vertebrae. Defective development of the sacral ridge and sacral roof was an essential feature but varied in extent. Deficiency of the postero-inferior angle of the fifth lumbar vertebra-It was noticed that the postero-inferior angle of the fifth lumbar vertebra appeared poorly formed in most patients. 
The shape of the corner did not become more defective as displacement progressed and in a few cases this part of the vertebral body was well formed despite severe displacement (Fig. 3). Thirty-six patients out of forty-six had a defective postero-inferior corner; the remainder appeared normal.

Myelography-Seven patients with neurological abnormalities were subjected to intrathecal myelography. Three showed a complete block (Fig. 11) to the passage of radiopaque medium at the level of the lumbo-sacral junction and four showed a partial block.

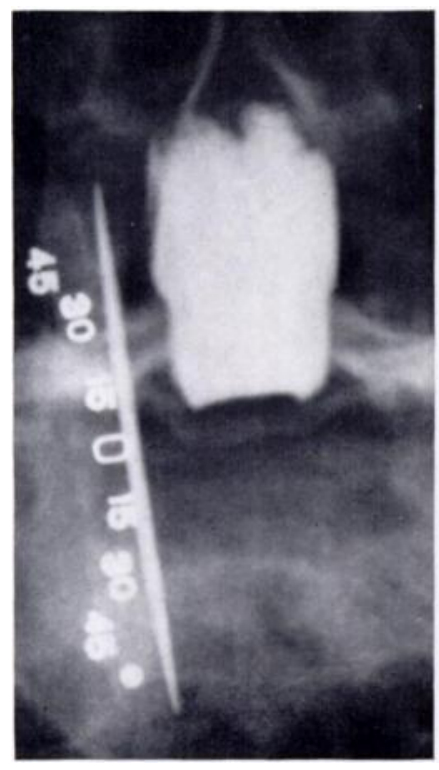

Intrathecal myelograph of the patient illustrated in Figures 1 and 2. Antero-posterior and lateral views showing complete block at the level of the neural arch of the fifth lumbar vertebra.

The gross radiographic appearance of the bone graft-An attempt was made to assess the time after operation at which incorporation of the graft was complete, using its radiographic appearance as a guide. The average time was four months, with a range of one to nine months. The gross radiographic appearance was found to be unreliable.

\section{MEASURING THE DISPLACEMENT}

Examination of the radiographs of patients with subluxation followed for several years without operation showed that a forward slip of the fifth lumbar vertebra on the upper surface of the first sacral body was followed by a rolling movement of the fifth lumbar vertebra. This can be compared with the motion of a car rolling slowly forward over the edge of a cliff. An attempt was made to measure both these features of the displacement, here referred to as "slip" and "roll".

Slip was measured by the method described by Newman (1965) which records not only the forward slip but also the downward movement of the postero-inferior angle of the fifth lumbar vertebra. Two lines are drawn on the lateral radiograph, one along the upper surface of the sacrum and the second of equal length at right angles to the first down the front of the sacrum; both lines are divided into ten equal parts. By studying the posterior and inferior margins of the fifth lumbar vertebra the point is estimated at which its postero-inferior angle would lie if it were present. This point is then plotted on both scales and the displacements added to give a score (Fig. 12). 
Roll was measured by noting the angle between lines of reference on the two vertebrae. Several methods were tried but the simplest and most reliable proved to be measurement of the angle between the lower surface of the first sacral body, shown by the epiphysial plate between the first and second sacral segments, and a diagonal drawn between the antero-superior
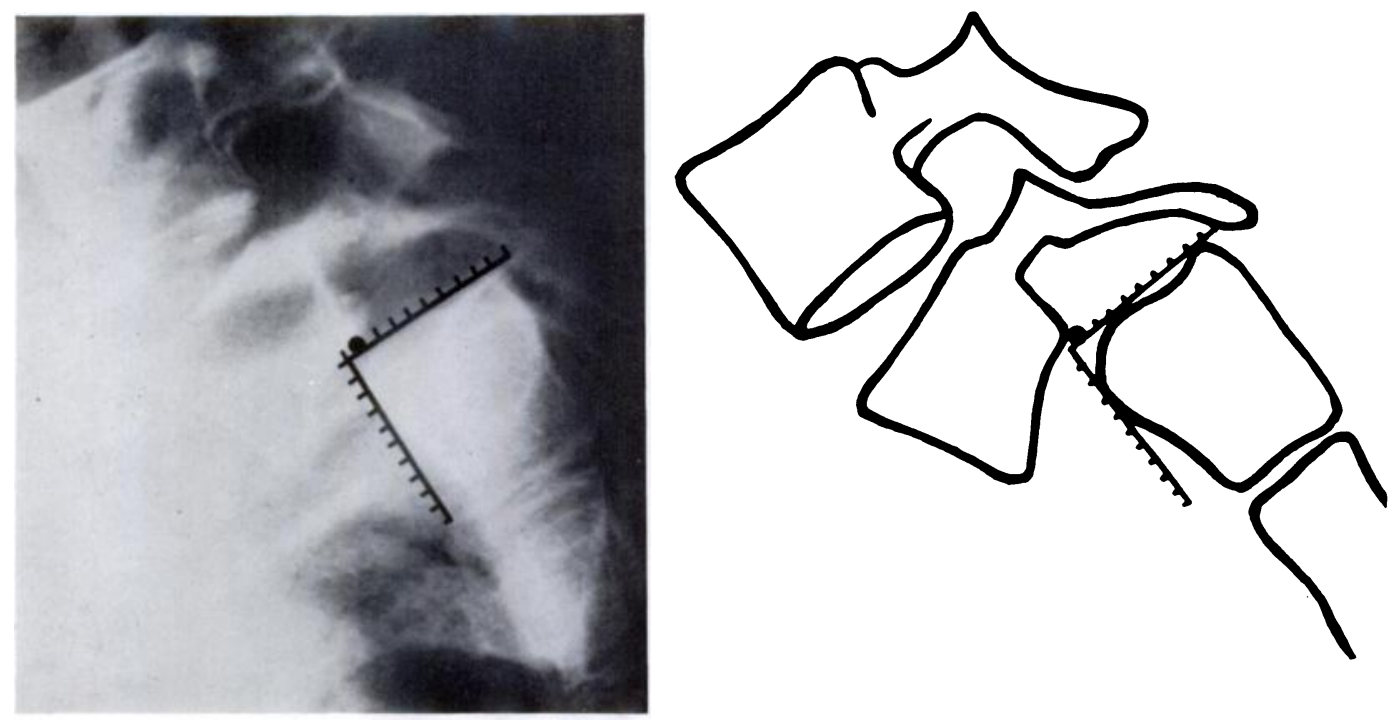

FIG. 12

Method of measurement of slip. The estimated position of the postero-inferior angle of the fifth lumbar vertebra has slipped 9 units on one scale and none on the other, to make a total of 9 units of slip.
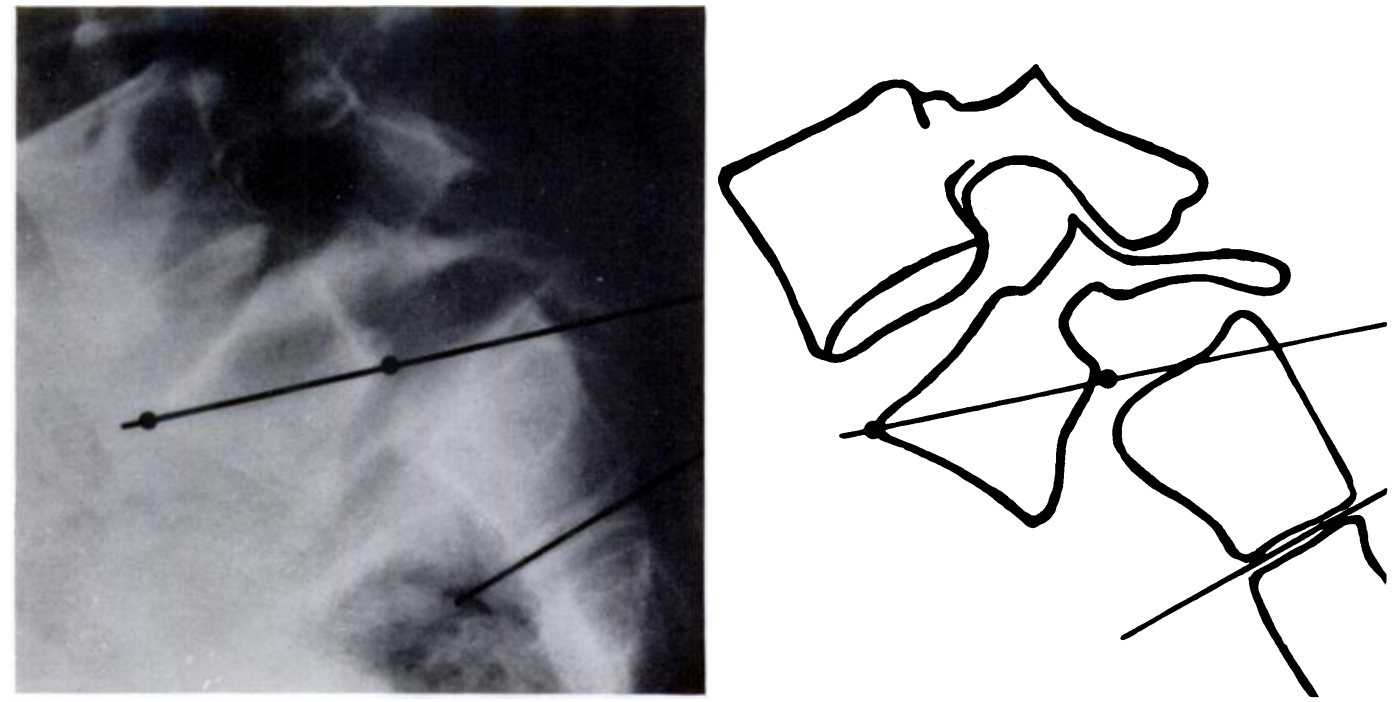

Fig. 13

Method of measurement of roll. One line is drawn through the lower edge of the first sacral body and another through the antero-superior angle of the fifth lumbar vertebra and the estimated position of its postero-inferior angle. The angle between the two lines is measured and recorded.

corner of the body of the fifth lumbar vertebra and the point used to represent the posteroinferior angle in the measurement of slip (Fig. 13).

This angle was measured on the radiographs of thirty normal men and women in the lateral recumbent position and the average was found to be 67.5 degrees, with a range of 
60 to 77 degrees. An increase in roll is shown by a decrease in the angle. Experiment showed that varying the spinal level at which the x-ray beam was centred and rotation of the patient did not alter this angle by more than 3 degrees. Despite this, radiographs were discarded if the technique was faulty.

Results-To study the rate of displacement before and after operation the amounts of slip and roll were measured on radiographs taken at the following stages. Six months or more before operation (No. 1 before operation); six weeks or less before operation (No. 2 before operation); six weeks or less after operation (No. 1 after operation); ten to fifteen weeks after operation (No. 2 after operation); five to seven months after operation (No. 3 after operation); nine to fifteen months after operation (No. 4 after operation); twenty-one to twenty-seven months after operation (No. 5 after operation); two years or more after oparation (No. 6 after operation).

Although radiographs taken at all eight stages were available in some patients, the number of direct comparisons was too small for statistical study. The largest comparable group contained seventeen patients with radiographs taken six weeks or less before operation, three months, six months and more than two years after operation (No. 2 before, No. 2 after, No. 3 after and No. 6 after). Table III shows the measurements in this group expressed as the annual rates of slip and roll during the intervals between successive measurements. The results show that in the first three months (No. 2 before to No. 2 after) after operation the slip tended to increase and the roll to decrease. Between three months and six months after operation (No. 2 after to No. 3 after) the slip increased further and the tendency of the roll to decrease was reversed. There is a statistically significant increase in the mean annual rate of roll during the period between three and six months after operation (No. 2 after to No. 3

TABLE III

The Means, Standard Deviations and Ranges of the Annual Rates of Slip and Roll during the Three Successive Intervals between Radiographs Taken at the Following Four Stages

Number 2 before operation (not more than 6 weeks before operation)

Number 2 after operation (10-15 weeks after operation)

Number 3 after operation (5-7 months after operation)

Number 6 after operation ( 2 years or more after operation)

The results of measurements from a group of seventeen patients are shown, together with the significances of the differences between means and the variance ratios

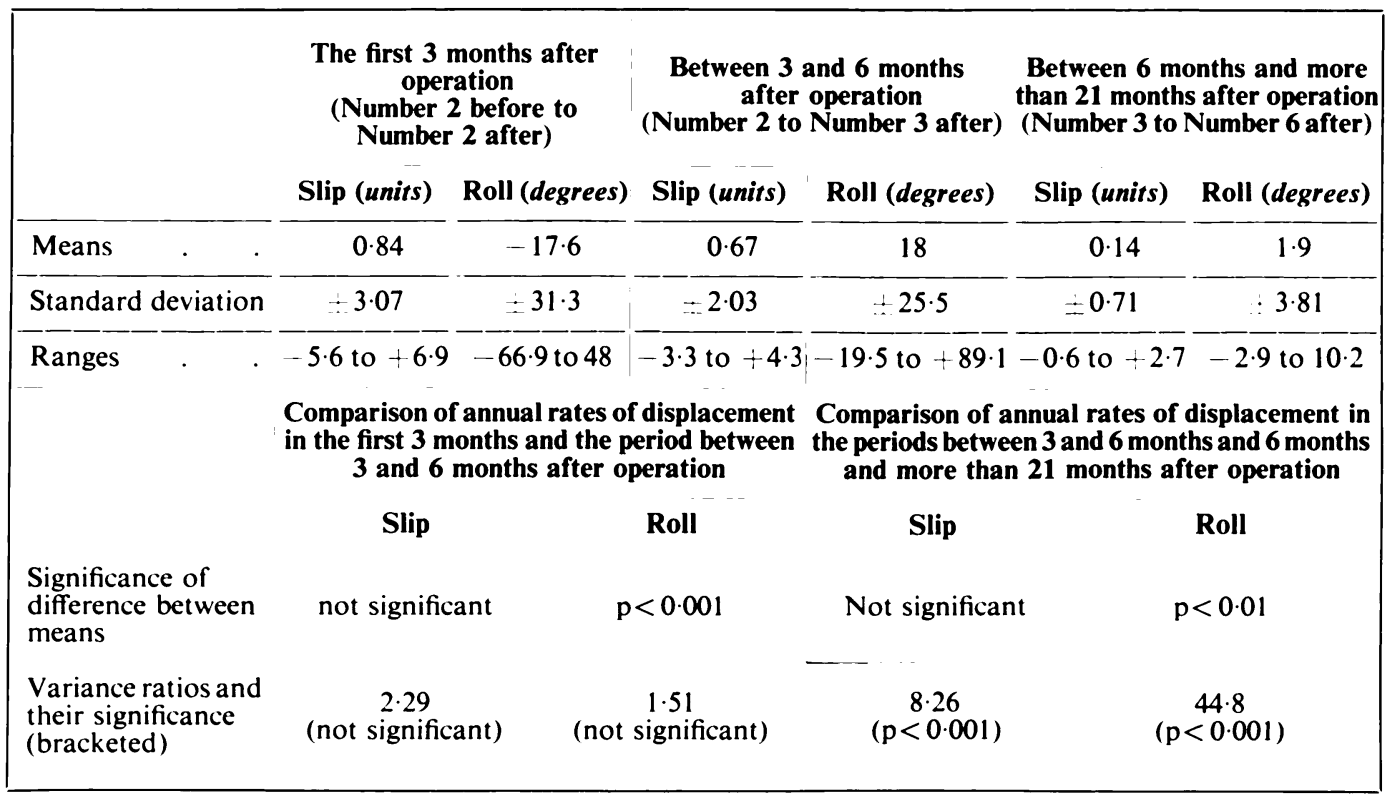

VOL. 53 B, NO. 4, NOVEMBer 1971 
after) compared with the first three-month period after operation (No. 2 before to No. 2 after). In the interval between radiographs taken six months after operation and more than two years after operation (No. 3 after to No. 6 after) both slip and roll continued to increase, but more slowly than in the period between three months and six months after operation (No. 2 after to No. 3 after). This is demonstrated by the statistically significant difference between the variance ratios of the measurements of the annual rates of slip and roll during these two periods.

The apparent decrease in the amount of roll during the first three months after operation was studied further by comparing measurements of twenty pairs of radiographs taken not more than six weeks before and six weeks after operation (No. 2 before to No. 1 after). The amount of slip had decreased in eleven out of twenty and increased in only two out of twenty, whereas the degree of roll had decreased in sixteen out of twenty and increased in two out of twenty. The average decrease in slip was 0.4 units (the difference between the means of paired observations was significant $-p<0.05$ ), whereas the average decrease in roll was 7.4 degrees $(p<0.001)$. The apparent improvement after operation was therefore confirmed.

The slower rate of displacement after operation was studied by comparing the annual rates of slip and roll before operation, during the second year after operation and more than two years after operation. Three groups of patients were available for comparison; twelve with two radiographs taken at least six months apart before operation (No. 1 before to No. 2 before), sixteen with two radiographs taken at least six months apart during the second post-operative year (No. 4 after to No. 5 after) and nineteen patients with radiographs taken at least one year apart more than two years after operation (No. 5 after to No. 6 after). The results are shown in Table IV. Before the operation the mean annual rates of slip and roll

TABLE IV

The Means, Standard Deviations and Ranges of the Annual. Rates of Slip and Roll for Three Groups during the Following Three Periods

1. A period of 6 months or more before operation (Number 1 before to Number 2 before)

2. A period of 6 months or more during the second post-operative year (Number 4 after to Number 5 after)

3. A period of 1 year or more at least 21 months after operation (Number 5 after to Number 6 after)

The results of measurements together with the significances of the differences between means, and the variance ratios

\begin{tabular}{|c|c|c|c|c|c|c|}
\hline \multirow{3}{*}{ Number of patients } & \multicolumn{2}{|c|}{$\begin{array}{l}\text { 1. Before operation } \\
\text { (Before } 1 \text { to before 2) }\end{array}$} & \multicolumn{2}{|c|}{$\begin{array}{l}\text { 2. The second year after } \\
\text { operation } \\
\text { (After } 4 \text { to after } 5 \text { ) }\end{array}$} & \multicolumn{2}{|c|}{ 3. More than 2 years after } \\
\hline & \multicolumn{2}{|r|}{12} & \multicolumn{2}{|c|}{16} & \multicolumn{2}{|c|}{19} \\
\hline & Slip (units) & Roll (degrees) & Slip (units) & Roll (degrees) & Slip (units) & Roll (degrees) \\
\hline Means . & $0 \cdot 88$ & $2 \cdot 4$ & $0 \cdot 24$ & $1 \cdot 1$ & $-0 \cdot 19$ & $0 \cdot 1$ \\
\hline Standard deviation & $\because 0.94$ & $\pm 10 \cdot 3$ & \pm 0.78 & \pm 5 & $\pm 0 \cdot 19$ & 10.9 \\
\hline \multirow[t]{3}{*}{ Ranges } & 0 to $2 \cdot 7$ & 18.9 to $+16 \cdot 1$ & -0.4 to 3 & $6 \cdot 7$ to +12 & -0.4 to +0.4 & -1.6 to +1.6 \\
\hline & \multicolumn{2}{|c|}{$\begin{array}{l}\text { Comparison of the rates of } \\
\text { displacement before operation } \\
\text { and during the second } \\
\text { post-operative year }\end{array}$} & \multicolumn{2}{|c|}{$\begin{array}{l}\text { Comparison of the rates of } \\
\text { displacement during the } \\
\text { second post-operative year } \\
\text { and more than } \\
\text { two years after operation }\end{array}$} & \multicolumn{2}{|c|}{$\begin{array}{l}\text { Comparison of the rates of } \\
\text { displacement before } \\
\text { operation and more than } \\
\text { two years after operation }\end{array}$} \\
\hline & Slip & Roll & Slip & Roll & Slip & Roll \\
\hline $\begin{array}{l}\text { Significance of differ- } \\
\text { ences between means }\end{array}$ & $\begin{array}{l}\text { Not } \\
\text { significant }\end{array}$ & $\begin{array}{l}\text { Not } \\
\text { significant }\end{array}$ & $\mathrm{p}<0.001$ & $\begin{array}{c}\text { Not } \\
\text { significant }\end{array}$ & $\mathrm{p}<0.001$ & $\begin{array}{c}\text { Not } \\
\text { significant }\end{array}$ \\
\hline $\begin{array}{l}\text { Variance ratios and } \\
\text { their significance } \\
\text { (bracketed) }\end{array}$ & $\begin{array}{c}1.44 \\
\text { (not } \\
\text { significant) }\end{array}$ & $\begin{array}{c}4.25 \\
(p<0.01)\end{array}$ & $\begin{array}{c}17 \\
(p<0.001)\end{array}$ & $\begin{array}{c}28 \\
(p<0.001)\end{array}$ & $\begin{array}{c}24 \cdot 6 \\
(p<0.001)\end{array}$ & $\begin{array}{c}119 \\
(p<0.001)\end{array}$ \\
\hline
\end{tabular}



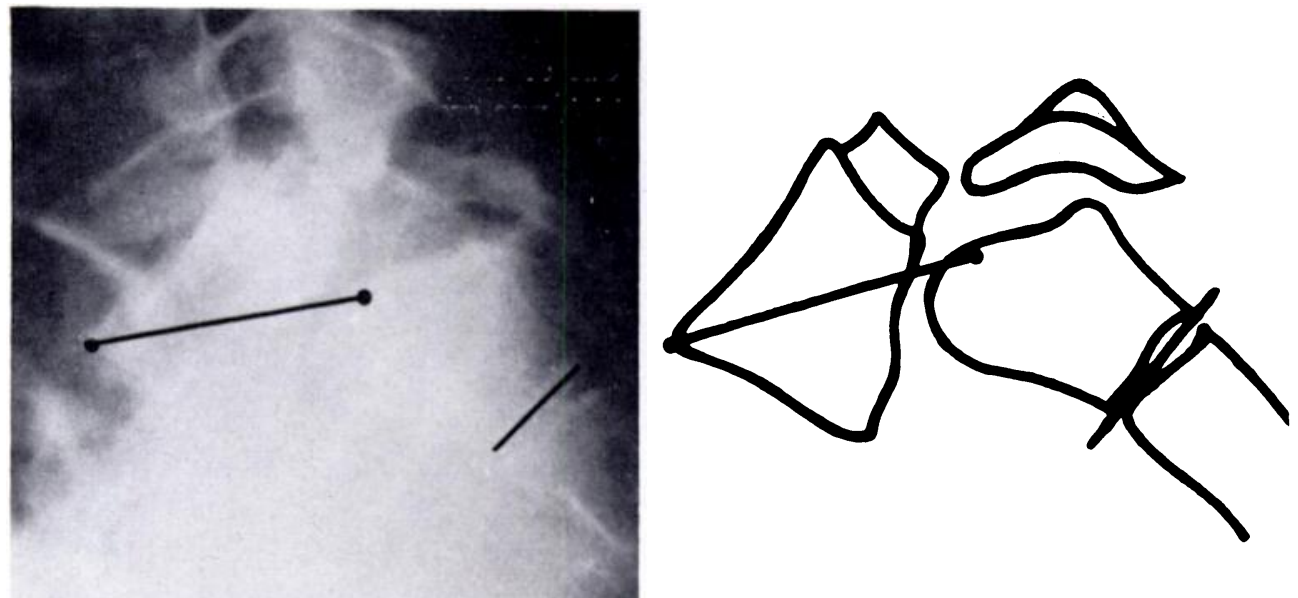

FIG. 14
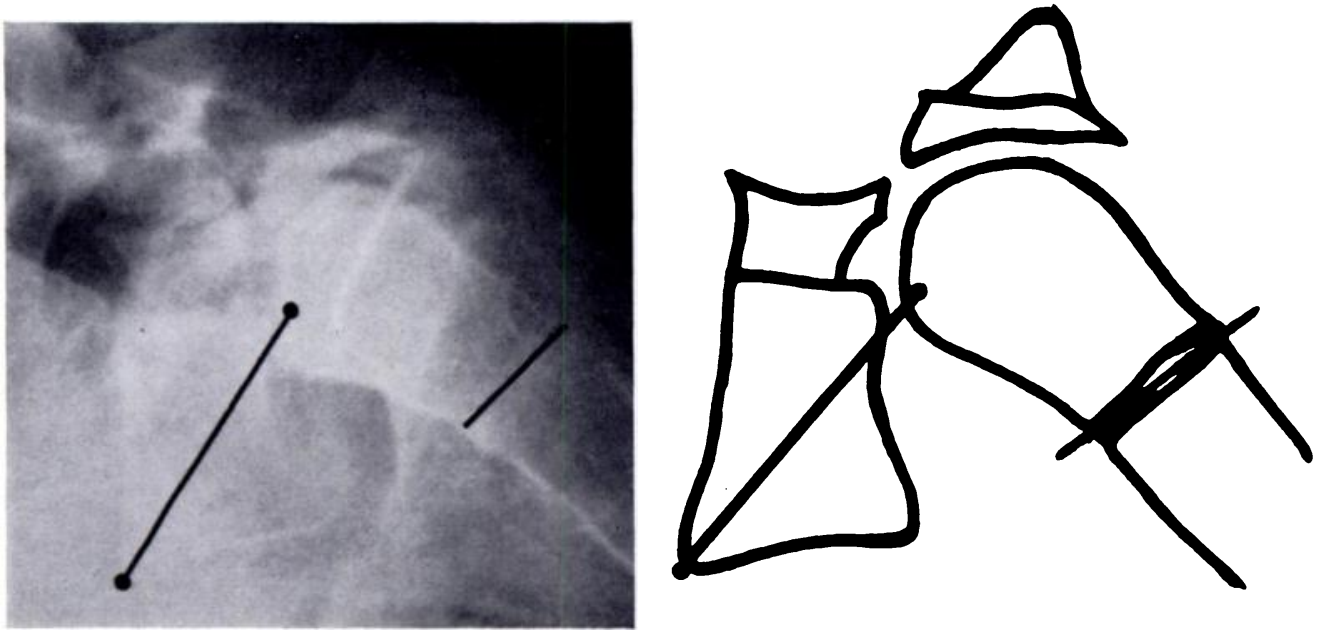

Fig. 15
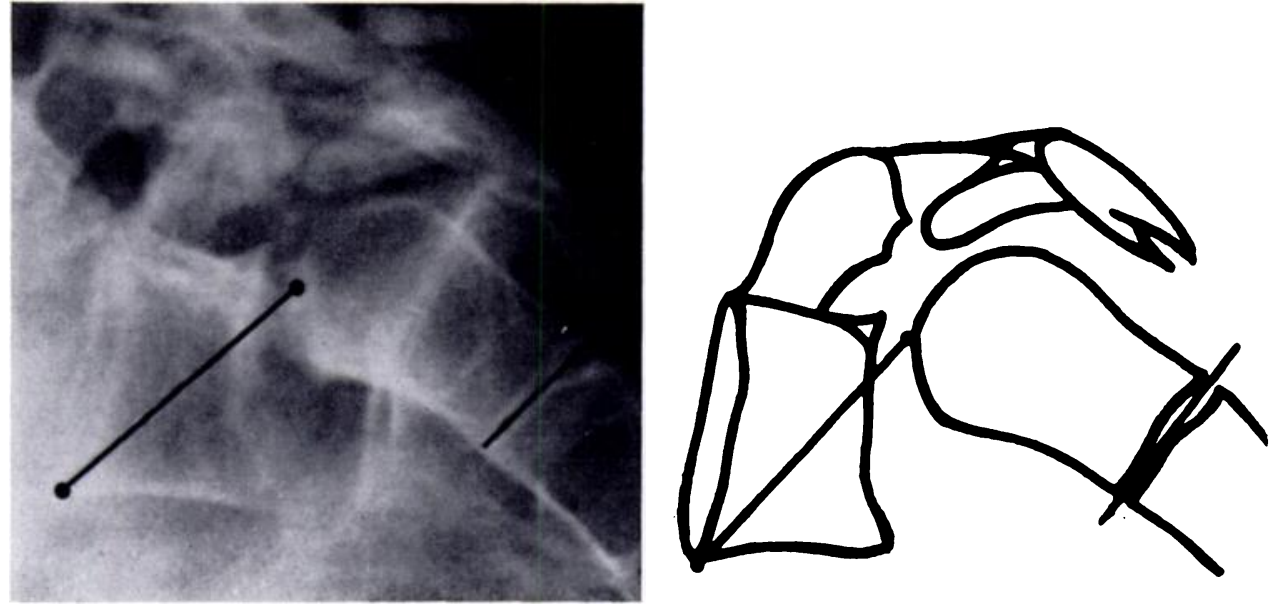

FIG. 16

The lines used for measurement of roll are marked on serial lateral radiographs of a single patient. Figure 14-Three years three months before operation: slip 6.5 units, roll 35 degrees. Figure $15-$ One month before operation: slip 10 units, roll 15 degrees. Figure $16-$ Ten weeks after operation: slip $8 \cdot 5$ units, roll 3 degrees.

VOL. 53 B. NO. 4, NOVEMBER 197J 
were 0.9 units and 2.4 degrees respectively; slip increased in eight out of twelve and was unchanged in four, while roll increased in six out of twelve, was unchanged in two and decreased in four. There was a wide variance which was greatly reduced in the second year after fusion when the annual rates of slip and roll had fallen to 0.2 units and 1 degree respectively. In the final period of one year or more, not less than twenty-one months after operation, no significant change in slip or roll was found, the differences all being within the limits of error.
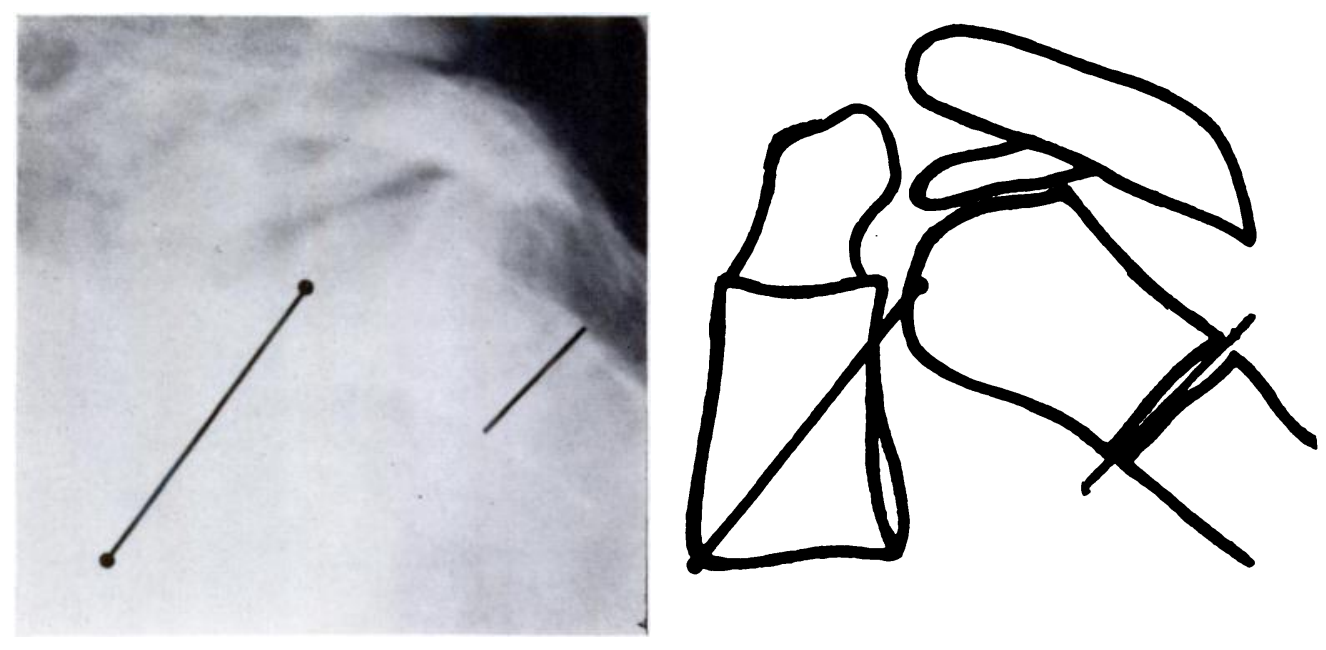

Fig. 17
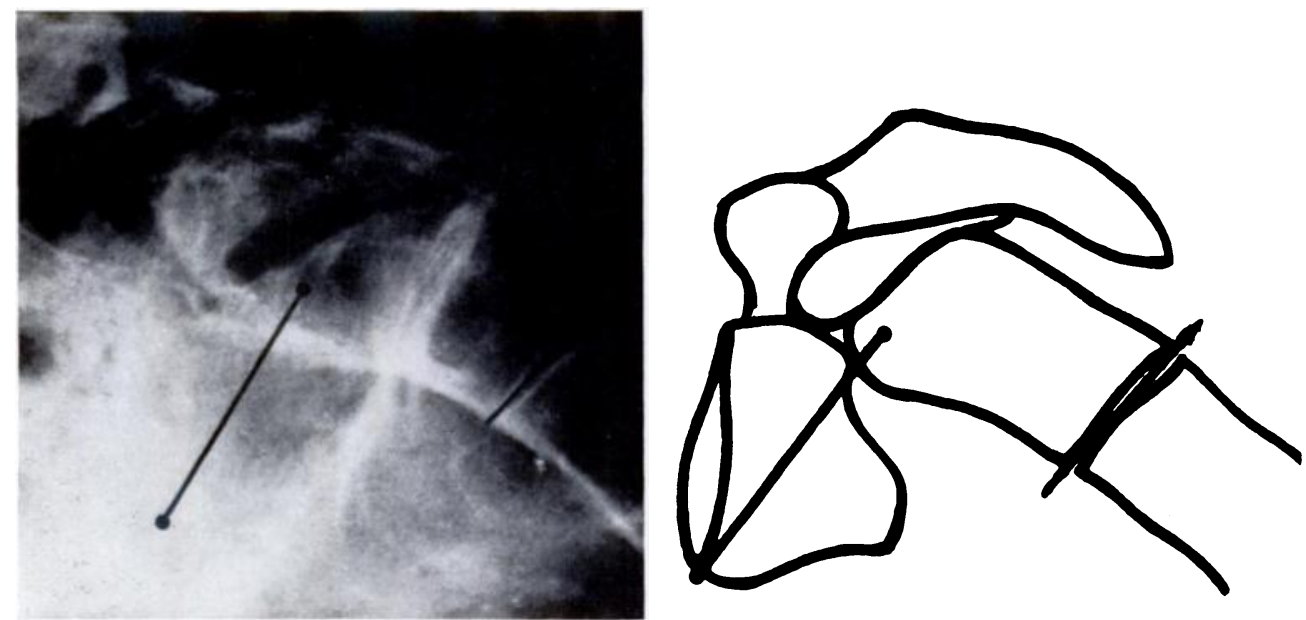

FIG. 18

The lines used for measurement of roll are marked on serial lateral radiographs of a single patient. Figure 17-Nine months after operation: slip 8.5 units, roll 7 degrees. Figure 18-Thirteen years six months after operation: slip $8 \cdot 5$ units, roll 8 degrees.

These results show that after an initial decrease both slip and roll continue to increase significantly for two years after spinal fusion, although much more slowly during the second year than before operation. Displacement does not continue for more than two years after operation. These points are illustrated by the series of measurements in Figures 14 to 18 and the graphs of Figures 19 and 20. 


\section{CLINICAL REVIEW}

Twenty-seven of the forty-six patients were examined; twenty-five had been subjected to spinal fusion, one anterior. Analysis of these twenty-five showed that they differed from

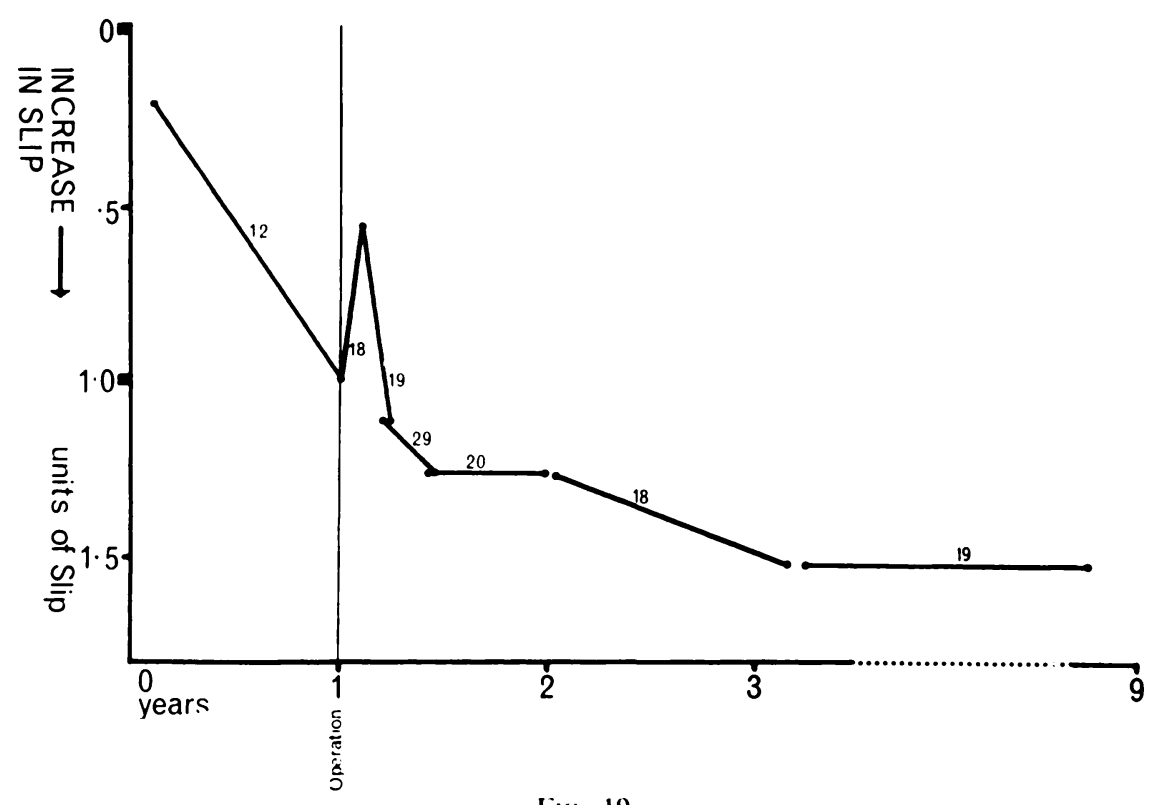

Fig. 19

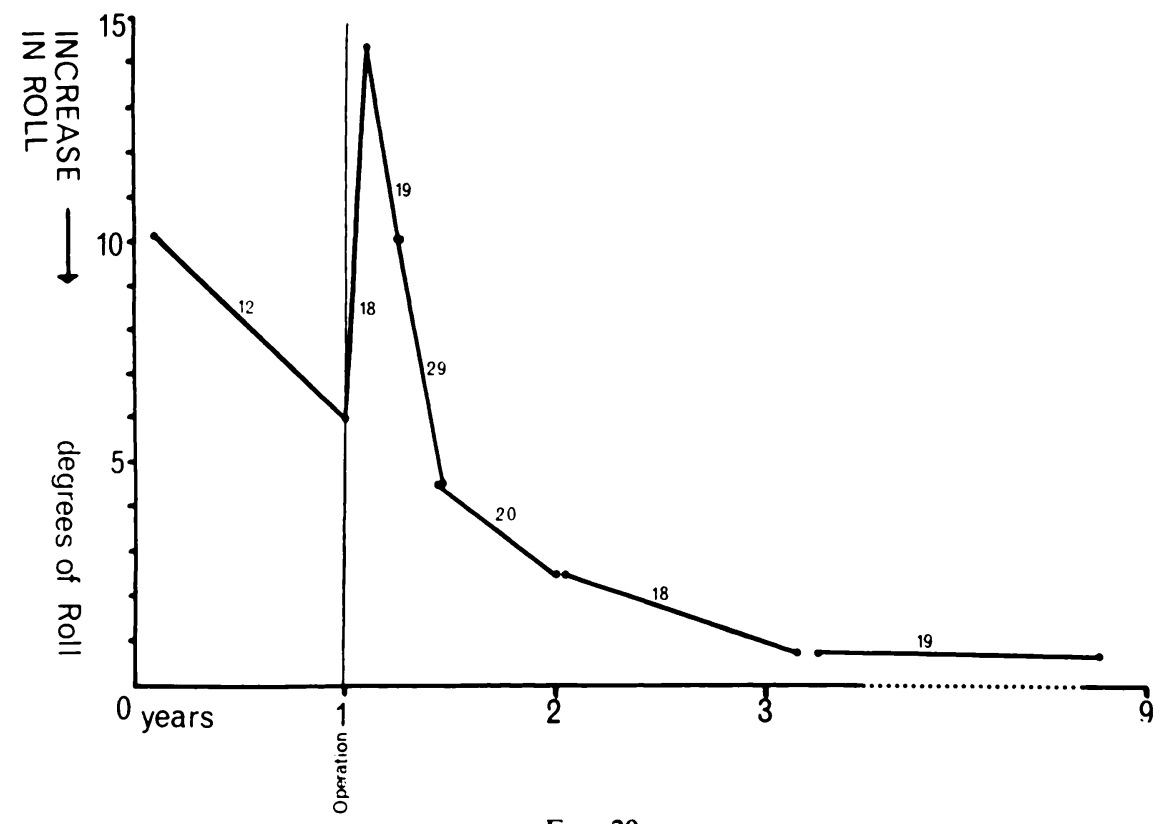

Fig. 20

Two series of graphs to show changes in slip and roll after spinal fusion. Pairs of radiographs at successive intervals were measured, and the mean change in slip and roll were plotted against time. The number of pairs in each group is shown. Figure 19-Change in slip. Figure 20-Change in roll.

the complete group of forty-six patients in two respects: they had undergone operation more recently and none had had attempted reduction. These patients were completely unselected and were similar to the complete group in all other respects.

VOL. 53 B, NO. 4, NOVEMBER 1971 
In the patients attending for review the average interval between onset of symptoms and operation was two years. Nine had been operated on within one year and eleven within two years of the onset of symptoms. The average interval between operation and review was six years, with a minimum of two years; twelve patients had been operated on more than five years before (Fig. 10).

Activities-All twenty-seven patients were carrying out a normal day's work. Twelve described their occupation as sedentary, twelve as light manual and three as heavy. Six patients had changed their occupation or planned occupation, but only two said their back had any influence on this decision.

Family history-Seven patients gave a family history of significant back trouble and in two cases lumbo-sacral subluxation was demonstrated radiologically in a parent.

Symptoms-Patients were asked if they had noticed any symptoms related to their back in the past year. Nine patients had experienced backache and in four it radiated to the buttock or thigh. Three of these also complained of slight tenderness at the donor site. Two of the nine patients with pain were the two who had not undergone operation. Eight of the nine said their symptoms were only occasional and very mild. The other had moderately severe pain which had commenced twenty-five years after fusion and may have been unrelated to the spondylolisthesis.

Four patients said that their backs were stiff but in none was this a problem. Eight had noticed minor sensory changes, but again none was troubled by them.

Twenty-four patients stated that their backs did not restrict them in any activity and many had returned to active sports, including football, rugby, hockey and riding. Others were keen gardeners. No patient had lost any time from work because of back trouble since operation.

Twenty-four of the twenty-five patients undergoing operation described their result as excellent. The one patient with recent deterioration said she was better than before her operation. Of the patients not operated upon, one had improved and one was unchanged.

Physical findings-All patients showed the typical deformity of lordosis, the apex of which was shifted cephalad, loss of pelvic tilt, palpable lumbo-sacral step and shortening of the trunk. The average pelvic tilt measured by the Wiles inclinometer was 18 degrees. Wiles (1937) found that the pelvic inclination increased steadily with growth until the age of eleven years, after which no change occurred, and that the average inclination in a healthy young adult population was 31 degrees in men and 28 degrees in women. Shortening of the trunk was estimated by measurement of crown-pubis and pubis-heel lengths, which in the normal adult are equal (Leonardo da Vinci). The average crown-pubis measurement was 77 centimetres and the average pubis-heel measurement 90 centimetres.

Six patients had mild scoliosis thought to be caused by rotation from unequal subluxation at the lumbo-sacral joints.

Five patients had tenderness at the donor site on the ilium. Only six patients could not touch their toes and all could reach below mid tibia. In no patient was straight leg raising less than 80 degrees.

Of nine patients with objective neurological signs, five had reflex changes and seven sensory changes; none had objective weakness.

Pregnancy-It was formerly suggested that severe lumbo-sacral subluxation was likely to cause obstetric problems by narrowing the pelvic inlet. In these twenty-seven patients fourteen normal pregnancies and four miscarriages had occurred. Labour was prolonged in two patients and a third had a Caesarean section for medical reasons. There was no foetal abnormality and no foetal mortality.

One patient became pregnant at the age of sixteen, and the lumbo-sacral subluxation increased during the pregnancy; she was operated upon after delivery. 


\section{DISCUSSION}

Indications for operation-This series consists almost entirely of patients subjected to spinal fusion. There is no adequate group of cases without operation to act as a control and it is therefore difficult to be certain that operation altered the progress of the condition. The clinical impression that growing patients with definite symptoms did not respond to conservative treatment was confirmed by our analysis, which show that only two of the thirty patients who underwent a period of conservative treatment achieved any worthwhile improvement, whereas all those undergoing spinal fusion were significantly improved, improvement being maintained in all but one patient. In older patients whose growth is complete, further displacement is unlikely and operation is indicated only after adequate conservative treatment has failed to relieve the symptoms.

In adolescent patients, in whom further deterioration and continuing symptoms are inevitable and inter-transverse spinal fusion can be relied upon to relieve symptoms, operation is the treatment of choice. From the results of this study it appears that there is no place for conservative treatment in patients with symptoms during the growth period.

Choice of operation-Anterior fusion was performed on only two patients, both of whom had a satisfactory result. This technique was abandoned because the exposure, particularly in the presence of severe degrees of slip, is technically difficult and possibly dangerous. The clinical results of posterior and inter-transverse fusion leave so little to be desired that this technique has been continued. A posterior approach also has the advantage that if exploration of the spinal canal is necessary it can easily be performed through the same incision.

Pregnancy - We found no evidence to suggest that pregnancy is hazardous in patients suffering from lumbo-sacral subluxation, but the number of pregnancies (fourteen) was too small for this to be confirmed. It can certainly be said that the presence of lumbo-sacral subluxation does not preclude a normal delivery.

Time before fusion-The difficulty in deciding when bony union is complete after a spinal fusion is well known and the problems are reviewed by Adkins (1955). Even if it can be shown that movement no longer occurs at the site of operation, it cannot be said that bony union has taken place unless trabeculae can be seen crossing the site of fusion. It is difficult to see such trabeculae in the lumbar spine. Morris and Kerr (1959) used superimposition films in lateral and forward flexion and found that consolidation was complete at seven months. Forsyth, Alexander, Davis and Underdal (1959) and DePalma and Prabhakar (1966), without giving their criteria for fusion, found that consolidation appeared complete three to seven months after cervical and lumbar fusion respectively, but Calandruccio and Benton (1964) found that trabeculae did not cross the site of anterior lumbar fusion for at least a year.

Because of these difficulties we have not been able to give a "fusion rate". It can be said, however, that after two years no further displacement at the site of fusion could be demonstrated in the group as a whole, and that in no patient did displacement continue at the same rate as before operation. We have found a statistically significant rate of displacement in the second year after operation. This suggests that fusion is not complete under two years, and agrees with the observation of many patients in this study that their symptoms took over a year to resolve completely. Most patients at first stated that their symptoms were relieved from the date of operation, but careful questioning, particularly in the patients operated upon more recently, suggested that many had mild symptoms for up to two years after operation.

Reversal of displacement after operation-Slip and roll showed an unexpected change of direction in radiographs taken less than six weeks after operation. This improvement was not the aim of operation, and is probably the effect of recumbency. The operation itself, in which the patient lies prone, may also be a factor. This improvement after simple recumbency may be helpful if it is felt necessary to reduce the subluxation.

VOL. 53 B, NO. 4, NOVEMBER 1971 
Cause-Several adjacent bony structures are defective in development-the superior sacral facets, the roof of the sacral canal, the spine of the fifth lumbar vertebra and the posteroinferior angle of its body, and the pars interarticularis. This configuration is less stable than a normal lumbo-sacral junction, and displacement accelerates when the hormonal growth changes of puberty take place. Newman (1965) observed that the age at the onset of symptoms in patients with this condition was similar to that in patients with a slipped upper femoral epiphysis, in which condition the same hormonal mechanism has been postulated to account for the age incidence.

No patient had tufts of hair, subcutaneous lipomata, cutaneous sinuses, or any other manifestation of spinal dysraphism; this indicates that the etiology of these two conditions is different.

Defect in continuity of the pars interarticularis-The defect in continuity of the narrowed pars interarticularis is not always present in this type of spondylosisthesis while it is an essential feature of Group 2 spondylolisthesis (Newman 1963), in which there is an ununited stress fracture. No correlation could be found in the present series between the presence of a defect in the pars interarticularis and a history of trauma, although a history of trauma was common in patients whose symptoms began suddenly.

Family history-The parents of the patients were examined only if they had a history of back disorder, but two of the seven parents so examined had lumbo-sacral subluxation. These numbers are too small to be significant but a hereditary tendency to the condition is possible.

\section{CONCLUSIONS}

1. Forty-six cases of congenital spondylolisthesis (Newman's Group 1) have been studied. The diagnostic criteria were lumbo-sacral subluxation, deficient development of sacral neural arches and superior facets, and attenuation and elongation of the pars interarticularis, with or without a defect in continuity.

2. Intertransverse lumbo-sacral fusion is a safe and reliable method of treatment.

3. Stabilisation is not complete before two years.

4. Spinal fusion is indicated in all patients with significant symptoms during the period of growth, but in adult patients only if conservative treatment fails.

Our thanks are due to $\mathrm{Mr} \mathrm{P}$. H. Newman for his help and encouragement and for allowing us to study the patients under his care; to Dr J. D. G. Troup for his immense help with the preparation of our statistics; to Mrs M. A. Glen-Haig and her staff in the Medical Records Department of the Royal National Orthopaedic Hospital; to Mrs R. Frankel-Pollen for secretarial assistance; and to Mr R. J. Whitley of the Institute of Orthopaedics for his help with the illustrations.

\section{REFERENCES}

Adkins, E. W. O. (1955): Lumbo-sacral Arthrodesis after Laminectomy. Journal of Bone and Joint Surgery, 37-B, 208

Barash, H. L., Galante, J. O., Lambert, C. N., and Ray, R. D. (1970): Spondylolisthesis and Tight Hamstrings. Journal of Bone and Joint Surgery, 52-A, 1319.

Brailsford, J. F. (1929): Deformities of the Lumbosacral Region of the Spine. British Journal of Surgery, $16,562$.

Calandruccio, R. A., and Benton, B. F. (1964): Anterior Lumbar Fusion. Clinical Orthopaedics and Related Research, 35, 63.

Capener, N. (1932): Spondylolisthesis. British Journal of Surgery, 19, 374.

DePalma, A. F., and Prabhakar, M. (1966): Posterior-Posterobilateral Fusion of the Lumbosacral Spine. Clinical Orthopaedics and Related Research, 47, 165. 
Forsyth, H. F., Alexander, E., Jun., Davis, C., Jun., and Underdal, R. (1959): The Advantages of Early Spine Fusion in the Treatment of Fracture-dislocation of the Cervical Spine. Journal of Bone and Joint Surgery, 41-A, 17.

KiLIAN, H. F. (1854): Schilderungen neuer Beckenformen und ihres Verhaltens im Lehen. Mannheim: Verlag von Bassermann \& Mathy.

Meyerding, H. W. (1931): Spondylolisthesis. Journal of Bone and Joint Surgery, 13, 39.

Meyerding, H. W. (1938): Spondylolisthesis as an Etiologic Factor in Backache. Journal of the American Medical Association, 111, 1971.

Morris, H. D., and KerR, T. (1959): Lumbosacral Fusion: Results of a Simple Postoperative Regimen in 95 Cases. Southern Medical Journal, 52, 542.

Neugebauer, F. L. (1888): A New Contribution to the History and Etiology of Spondylolisthesis. Translated by F. Barnes. The New Sydenham Society. Selected Monographs, vol. 121. London: The New Sydenham Society.

Newman, P. H. (1963): The Etiology of Spondylolisthesis. Journal of Bone and Joint Surgery, 45-B, 39.

Newman, P. H. (1965): A Clinical Syndrome Associated with Severe Lumbo-sacral Subluxation. Journal of Bone and Joint Surgery, 47-B, 472.

Phalen, G. S., and Dickson, J. A. (1961): Spondylolisthesis and Tight Hamstrings. Journal of Bone and Joint Surgery, 43-A, 505.

Wilfs, P. (1937): Postural Deformities of the Anteroposterior Curves of the Spine. Lancet, i, 911.

VOL. 53 B, NO. 4, NOVEMBER 1971 